\title{
Long-term effects of tri-n-butyl-tin on the function of a marine sediment system
}

\author{
I. Dahllöf ${ }^{1, *}$, H. Blanck ${ }^{2}$, P. O. J. Hall ${ }^{1}$, S. Molander ${ }^{3}$ \\ ${ }^{1}$ Department of Analytical and Marine Chemistry, Göteborg University, 41296 Göteborg, Sweden \\ ${ }^{2}$ Department of Plant Physiology, Göteborg University, Box 461, 40530 Göteborg, Sweden \\ ${ }^{3}$ Department of Technical Environmental Planning, Chalmers University of Technology, 41296 Göteborg, Sweden
}

\begin{abstract}
The effect of tri- $n$-butyl-tin (TBT) was studied in a 5 mo experiment using intact coastal sediment communities in a boxcosm system. TBT-spiked sediment was added in a geometrical series between 0.0065 and $300 \mu \mathrm{mol}$ TBT $\mathrm{m}^{-2}$ to a sediment that already had a background TBT concentration. Fluxes of ammonium, nitrate, phosphate, silicate and oxygen were used as effect indicators for the entire sediment system, integrating the function of all fauna and micro-organisms present. Changes in flux patterns were analysed in order to evaluate the effect of TBT on the whole sediment system using a non-parametric analysis of similarities (ANOSIM), based on Bray-Curtis similarity indices. Effects

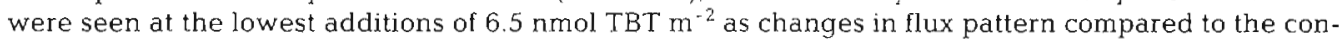
trol sediments. The separate nutrient fluxes were also evaluated, showing an early response in a reduced ammonium flux and a stimulated nitrate flux for most of the TBT additions. The initial response indicated immediate effects on the microbial part of the sediment community. The fluxes changed with time in all sediment boxes, but the changes were different in sediments with added TBT compared to the control sediment. These changes showed that the heterotrophic capability to degrade organic matter and autotrophic nitrification was reduced during the 5 mo of the experiment. In the 3 highest additions, the abundance of macrofauna was reduced at the very beginning of the experiment, whereas fauna in the intermediate additions seemed to become stressed with time as indicated by an increased oxygen consumption. This study shows that minute additions of fresh TBT to an already contaminated sediment have effects on the function of the sediment system at nominal concentrations of nmol of TBT added per square metre. These additions were well below the current detection limits for TBT in sediments
\end{abstract}

KEY WORDS: TBT · Long-term effects · Function - Marine sediment - Nutrient and oxygen fluxes

\section{INTRODUCTION}

Most ecotoxicological studies of tri- $n$-butyl-tin (TBT) in marine sediment are on isolated bacteria or on single species in manipulated sediments (Cooney \& Wuertz 1989, Bergeron et al. 1993, Miller \& Cooney 1994, Jude et al. 1996, Austen \& McEvoy 1997, Meador et al. 1997). The main problems with these kinds of studies are the difficulties of finding the right test species and of extrapolating the results to the ecosystem level (Cairns 1983, Kimball \& Levin 1985, Landis et al. 1997). Our approach was instead to study effects of TBT on the function of the entire sediment community,

•E-mail: ingela@amc.chalmers.se including both fauna and micro-organisms, using intact sediment cores. This approach has the advantage that both direct and indirect effects, as well as acute and more persistent effects, are taken into account. Furthermore, the results can be extrapolated more confidently to natural sediments since the community is intact and the manipulation of the sediment is kept to a minimum. We chose to study how TBT affects one of the main functions of a coastal marine sediment - the degradation of organic matter from pelagic organisms and recirculation of nutrients to the water mass (Libes 1992).

Bacteria are responsible for most of the mineralisation of organic matter. The products of mineralisation, such as inorganic species of nitrogen, phosphorus and 


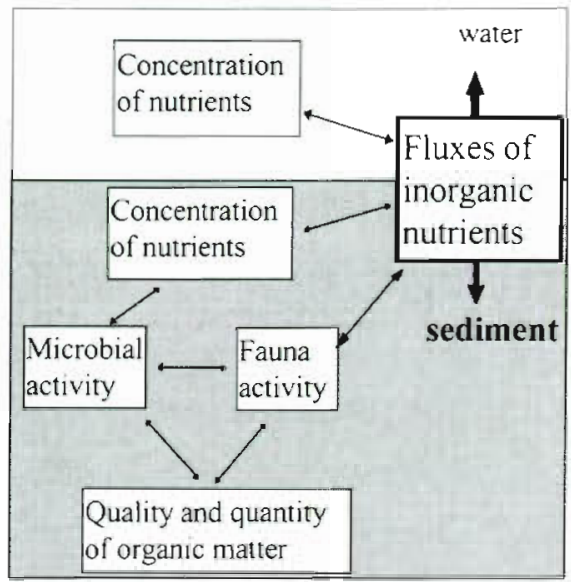

Fig. 1. Fluxes of nutrients are the integrated result of the interactions between micro-organisms and fauna and their abiotic environment

silica, build up in the sediment, causing a concentration difference between the sediment and the overlying water. Likewise, dissolved substrates used for mineralisation, such as oxygen and nitrogen, will decrease in the sediment, again causing a concentration difference between the water and the sediment. These concentration differences induce fluxes of the dissolved substrates and products of mineralisation across the sediment-water interface. Fauna play an important role in regulating these fluxes by ventilating burrows, changing the quality of organic matter through digestion, displacing particles while feeding, and by physically moving through the sediment. This means that the fluxes of nutrients and oxygen over the sediment-

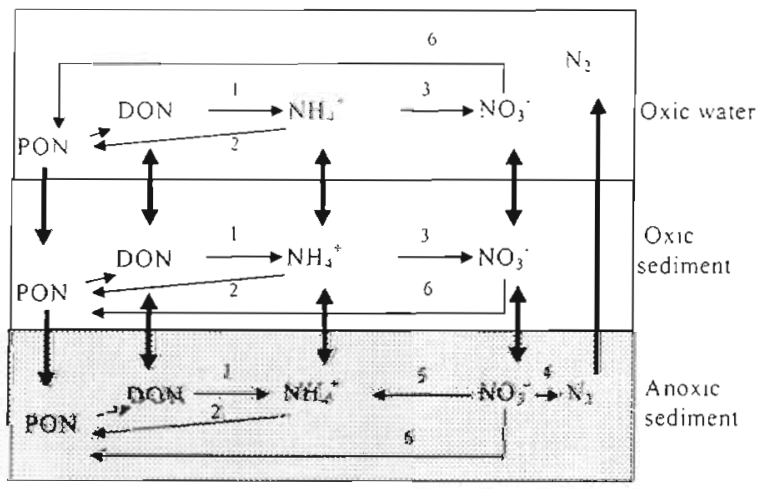

Fig. 2. A model of the nitrogen cycle. Thin arrows with numbers represent the different processes in the nitrogen cycle: (1) ammonification, (2) assimilation of ammonium, (3) nitrification, (4) denitrification, (5) dissimilatory nitrate reduction and (6) assimilatory nitrate reduction. Thicker arrows indicate the fluxes that can result from these processes water interface reflect the activity of the entire sediment system, suggesting fluxes to be an appropriate ecotoxicological effect indicator (Fig. 1). Another advantage with fluxes as effect indicators is that nondestructive sampling can be performed during the experiment. Since we did not wish to further manipulate the sediment or the sediment community during the experiment, non-destructive sampling was a prerequisite. Fluxes of nutrients have already been used to detect effects of TBT on the microbial part of the sediment community in short-term experiments using sieved sediment in small-scale incubations (Dahllöf et al. 1999).

When using fluxes as effect indicators, 3 major complications must be taken into account, namely coupled reactions (Levin 1989), functional redundancy (Pratt \& Cairns 1996), and interactions between micro-organisms and fauna (Aller 1982, 1994, Santschi et al. 1990). Many inorganic species of nutrients are products of mineralisation as well as substrates for mineralisation and for assimilation processes. The most obvious examples are from the nitrogen cycle, where both ammonium and nitrate are substrates as well as products (Fig. 2). This means that effects of toxicants on one process can indirectly be reflected in other processes and it is difficult to know where the primary effect is. The second complication, the concept of functional redundancy, means that even if an organism performing a specific function is affected, another organism can step in and perform the same function. The functional redundancy is, however, not immediate and not always complete, but it can make effects look less important than they really are. It is therefore crucial to include structural parameters if possible in order to fully evaluate the effect of toxicants. This was also done at the end of the experiment. The third complication is the interaction between micro-organisms and fauna, where effects on one party can obscure effects on the other. For example, increased fauna activity induced by stress can, due to increased ventilation, stimulate nitrification and thereby change the flux of both ammonium and nitrate, even if these processes are not themselves affected. These 3 complications can make detection of effects difficult when using single effect variables. Firstly, it would be difficult to choose the best effect variable before the experiment and secondly, the responses are likely to be non-linear since the effect parameters are the combined result of many processes in sequence. However, evaluating the flux pattern increases the chance of detecting the effects, as it is highly unlikely that all changes are compensated for. The flux pattern in this experiment consisted of the nutrient fluxes for all boxes on 6 different occasions and oxygen fluxes for all boxes on 5 different occasions. By using multivariate analysis, all fluxes 
(variables) can be evaluated simultaneously, and the effect on the sediment system can be detected even if effects on individual fluxes are small and non-linear. In this study we used a multivariate non-parametric analysis of similarities (ANOSIM), where differences in the Bray-Curtis similarity index between treatments can be tested.

A regression design was chosen for the experiment, with replication of the control sediments only, so that small increases in TBT additions could be made and yet a large concentration span could be covered. Since the experiment was run over 5 mo and the sampling was non-destructive, sufficient data could still be collected in order to use multivariate analysis to evaluate the effect of TBT on the function of the entire sediment community.

The TBT that reaches the sediment mainly originates from boat paint where it serves as an anti-fouling component. Since the late $80 \mathrm{~s}$, TBT has been banned from use on boats smaller than $25 \mathrm{~m}$ in most European and North American countries (Champ \& Wade 1996), while it is still approved for use on larger vessels. TBT was first shown to be a hazard to non-target organisms in the marine environment when commercially farmed oysters became sterile and produced abnormally thickened shells (Alzieu et al. 1981-1982). Further investigations have shown that TBT is toxic to many marine organisms (Bryan \& Gibbs 1991, Blanck \& Dahl 1996, Austen \& McEvoy 1997).

In this experiment we added TBT to a sediment with a background concentration of 83 pmol TBT g ${ }^{-1}$ dry sediment $\left(\sim 27 \mathrm{ng} \mathrm{g}^{-1}\right)$, which is a moderately contaminated site according to Dowson et al. (1993), with the aim of describing the changes in function to the sediment community due to TBT.

\section{MATERIAL AND METHODS}

The boxcosm system. The design and function of the boxcosm system was described by Molander et al. (unpubl.). In short, the box cosm system consisted of intact sediment cores fitted in Plexiglas boxes $(0.5 \times$ $0.5 \times 0.4 \mathrm{~m}$ ) with a circulating overlying water mass (Fig. 3). The sediment depth was around $30 \mathrm{~cm}$ and the water depth was about $10 \mathrm{~cm}$. A peristaltic pump generated a water flow through each box of about 100

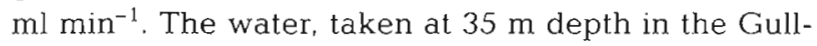
mar Fjord, supplied the box with oxygenated water, and to some extent also with organic matter. A perpendicular water circulation driven by a standard aquarium pump prevented the build-up of nutrient and oxygen gradients, and ensured a homogenous water mass for sampling. The circulation flow gave a bottom current of about $0.5 \mathrm{~cm} \mathrm{~s}^{-1}$. The boxes were

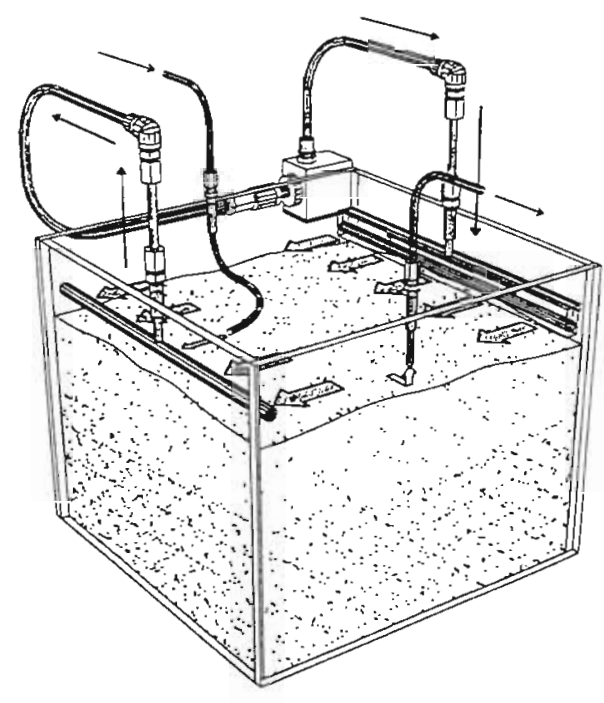

Fig. 3. The box holding the intact sediment. Circulation flow (broad arrows) is placed perpendicular to the through flow water (thin arrows)

immersed in large water-filled tubs containing 5 boxes each. Temperature was controlled both in the flow-through water and in the water surrounding the boxes as well as in the air.

Experimental set-up. The experimental design consisted of 5 control boxes and 15 TBT-treated boxes without replication. The additions of TBT in the treatments followed a regression model with a logarithmic increase of 2 , from 0.0065 to $300 \mu \mathrm{mol} \mathrm{TBT} \mathrm{m} \mathrm{m}^{-2}$ (Table 1).

Twenty boxes were brought in on December 16 , 1996, and allowed to acclimatise for $4 \mathrm{~d}$ before adding the TBT. The sampling site was situated in the Gullmar Fjord on the Swedish west coast, on a sloping soft-bottom plain between the harbour of Lysekil and the deepest part of the fjord, Alsbäck. The dominating macrofauna species at this station are brittlestars Amphiura spp., heart urchins Brissopsis lyrifera, and polycheates Maldane sarsi and Heteromastus filiformis. The average $(n=14)$ porosity and water content was $0.84 \pm 0.1\left(\mathrm{ml}\right.$ water $\mathrm{ml}^{-1}$ sediment) and $0.74 \pm 0.1$ (g water $\mathrm{g}^{-1}$ sediment), respectively. Organic carbon content was $2.91 \pm 0.06 \%$ and total nitrogen content $0.33 \pm 0.02 \%$ of the dry weight $(\mathrm{dw})$. The depth was 60 $\mathrm{m}$, which is below the pycnocline. All boxes were randomly assigned a treatment number. The boxes were kept at the in situ temperature of $5^{\circ} \mathrm{C}$ at all times, and in the dark, except when sampling for flux measurements.

Six flux studies were performed between December 1996 and May 1997, and additional studies were performed at the end of the experiment in order to study changes in structure and induced tolerance. 
Table 1. Added and measured TBT concentrations in sediment boxcosms. The first 2 columns represent calculated additions of TBT in nmol and $\mu \mathrm{g}$ TBT $\mathrm{m}^{-2}$ Columns 3 and 4 represent the calculated TBT concentrations achieved if the TBT has stayed within the top centimetre without any losses. Columns 5 to 8 show the measured concentrations of TBT and DBT respectively in the top centimetre of the boxes at the end of the experiment and the last column shows the calculated dilution of the added TBT. Values in bold represent background concentrations at the sediment sampling site. Values in italic represent boxes lost during the experiment

\begin{tabular}{|c|c|c|c|c|c|c|c|c|c|c|}
\hline \multicolumn{2}{|l|}{$\begin{array}{l}\text { TBT- } \\
\text { addition } \\
\text { no. }\end{array}$} & \multicolumn{2}{|c|}{ Added TBT m-2 } & \multicolumn{2}{|c|}{$\begin{array}{c}\text { Added TBT } \\
\text { in top cm } \\
\left(\mathrm{nmol} \mathrm{g} \mathrm{g}^{-1} \mathrm{dw}\right)\left(\mu \mathrm{gg} \mathrm{g}^{-1} \mathrm{dw}\right)\end{array}$} & \multicolumn{2}{|c|}{$\begin{array}{c}\text { Measured TBT } \\
\text { in top cm } \\
\left(\mathrm{nmol} \mathrm{g}{ }^{-1} \mathrm{dw}\right)\left(\mu \mathrm{g} \mathrm{g} \mathrm{g}^{-1} \mathrm{dw}\right)\end{array}$} & \multicolumn{2}{|c|}{ 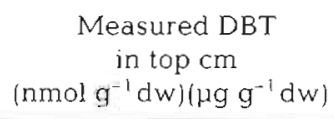 } & \multirow[t]{2}{*}{$\begin{array}{l}\text { Dilution } \\
\text { of added } \\
\text { TBT }\end{array}$} \\
\hline Control & 1 & 0 & 0 & 0 & 0 & 0.08 & 0.03 & 0.111 & 0.036 & \\
\hline Control & 5 & 0 & 0 & 0 & 0 & 0.09 & 0.03 & 0.092 & 0.03 & \\
\hline Control & 8 & 0 & 0 & 0 & 0 & - & - & - & - & \\
\hline Control & 11 & 0 & 0 & 0 & 0 & 0.08 & 0.03 & 0.141 & 0.046 & \\
\hline 1 & 13 & 0.0065 & 0.0020 & 0.0022 & 0.0007 & 0.10 & 0.03 & 0.154 & 0.05 & \\
\hline 2 & 16 & 0.014 & 0.0046 & 0.0047 & 0.002 & 0.06 & 0.02 & 0.07 & 0.02 & \\
\hline 3 & 20 & 0.03 & 0.00976 & 0.01 & 0.0033 & 0.06 & 0.02 & 0.077 & 0.025 & \\
\hline 4 & 18 & 0.065 & 0.021 & 0.022 & 0.007 & - & - & - & - & \\
\hline 5 & 19 & 0.143 & 0.046 & 0.047 & 0.015 & - & - & - & - & \\
\hline 6 & 2 & 0.3 & 0.097 & 0.1 & 0.0325 & 0.07 & 0.02 & 0.092 & 0.03 & \\
\hline 7 & 9 & 0.64 & 0.21 & 0.21 & 0.0696 & 0.07 & 0.02 & 0.077 & 0.025 & \\
\hline 8 & 4 & 1.40 & 0.46 & 0.46 & 0.1522 & 0.10 & 0.034 & 0.086 & 0.028 & 19.12 \\
\hline 9 & 6 & 3 & 0.98 & 1 & 0.3255 & 0.14 & 0.046 & 0.092 & 0.03 & 16.31 \\
\hline 10 & 3 & 6.40 & 2.09 & 2.14 & 0.6959 & 0.19 & 0.061 & 0.101 & 0.033 & 19.90 \\
\hline 11 & 7 & 13.70 & 4.469 & 4.574 & 1.4878 & 0.41 & 0.135 & 0.16 & 0.051 & 13.65 \\
\hline 12 & 12 & 30 & 9.76 & 10 & 3.2549 & 1.06 & 0.346 & 0.25 & 0.081 & 10.17 \\
\hline 13 & 17 & 64.10 & 20.88 & 21.4 & 6.9589 & - & - & - & - & - \\
\hline 14 & 14 & 137.10 & 44.638 & 45.7 & 14.878 & 8.08 & 2.63 & 0.92 & 0.301 & 5.71 \\
\hline
\end{tabular}

Addition of TBT. Sixteen stock solutions of TBT in filtered sea water were prepared with acetone as cosolvent. The stock solution for the controls contained filtered sea water and acetone. $250 \mathrm{~g}$ of sediment from the sampling site was sieved through a $1 \mathrm{~mm}$ sieve and put in a high density polythene bottle, and the stock solution was added to make up $1 \mathrm{l}$ of sediment slurry. The concentration of acetone was 1 ppm in the slurry and was further diluted as the slurry was added to the water mass in the box. The amount of sediment was calculated to give a maximum $1 \mathrm{~mm}$ increase in sediment height when settled on the sediment surface. The sediment slurry was mixed over $48 \mathrm{~h}$ to make sure that the TBT evenly adsorbed to the particles. A pre-study to determine both percentage adsorbed and time for absorption equilibrium was made using the sediment extraction technique with GC/MS for detection by Waldock et al. (1989). We found that it took less than $24 \mathrm{~h}$ for the TBT to adsorb to marine sediment particles and the recovery from the sediment in the slurry was 85 to $110 \%$. More thorough experiments concerning adsorption to sediment particles have shown that $89 \%$ of TBT absorbed within $10 \mathrm{~min}$ and reached equilibrium after 2 h (Langston \& Pope 1995).

The slurry was added by slowly pouring it onto a sheet of Plexiglas while moving the sheet horizontally across the sediment surface in order to evenly distribute the slurry. It took $48 \mathrm{~h}$ before the overlying water was clear, the lids could be mounted on the boxes and both the flow-through water and circulation flow could be turned on.

Flux measurements. The fluxes of nutrients and oxygen were measured by turning the flow-through water off, while maintaining the circulation flow, and measuring the increase or decrease of nutrients and the decrease of oxygen in the overlying water mass on 5 to 7 occasions over a $6 \mathrm{~h}$ period. The water mass was sampled by momentarily turning the flow-through water on and at the same time turning the circulation flow off. This procedure gave a homogenous sample of the water mass, while erroneous sampling of the refill water was avoided. The oxygen concentration was always kept above $220 \mu \mathrm{M}$ and seldom decreased more than $20 \%$ from the original value during the flux measurements.

Oxygen was sampled in a $12 \mathrm{ml}$ serum bottle, Winkler reagents were added and the bottle was sealed, shaken and kept in the dark at $5^{\circ} \mathrm{C}$ until analysis. Three replicate samples for nutrient analysis were sampled after the oxygen and analysed immediately. The flux was calculated using regression analysis on the increase/decrease of the species of interest with time (Fig $4 \mathrm{a}, \mathrm{b}$ ). A positive flux indicates a flux out of the sediment and a negative flux a flux into the sediment.

Chemical analysis. Oxygen was determined using the Winkler technique modified for a small sample 
volume. All nutrients, ammonium, nitrate, phosphate and silicate, were analysed on an automatic nutrient analyser (TRAACS 800, Braun and Luebe, Germany). Nitrate analysis was run as the sum of nitrate and nitrite, where the nitrite concentration was considered to be negligible in highly oxygenated water.

TBT in the top centimetre of the sediment was analysed at the end of the experiment. The sediment was frozen in polythene vials prior to analysis. Analyses were performed at The Centre for Environment, Fisheries, and Aquaculture Sciences (CEFAS) in Burmhamon-Crouch, UK. TBT and DBT were extracted with alkaline methanol $(1 \% \mathrm{NaOH})$ and sodium borohydride was added. The resulting TBT and DBT hydrides were extracted into a hexane phase and subsequently analysed using GC/FDP (Waldock et al. 1989). Tripropyl-tin was used as internal standard and the detection limit was around $0.015 \mathrm{nmol} \mathrm{g}^{-1}$ dry sediment.

Statistical analysis. To detect effects on system level, changes in flux pattern were analysed by calculating the Bray-Curtis similarity index. The Bray-Curtis index is normally used for determining similarity between sites with regard to species composition (Clarke \& Warwick 1994). The index is a pair-wise comparison between sites, with regard to number of species and their abundance. Using the Bray-Curtis index in this experiment means that boxes are considered as sites, and fluxes from all 6 occasions are considered as species, thus calculating the similarity between boxes with regard to flux pattern. The data were first normalised by ranking the fluxes before they were entered into the matrix to compensate for differences in flux size between different types of nutrients and to avoid negative values. The Bray-Curtis similarity index between each TBT addition and the 4 controls was then calculated using Primer statistical software developed by Plymouth Marine Laboratory, UK. The resulting similarity matrix was graphically presented using non-metric multi-dimensional scaling (MDS). Differences between groups, as indicated in the MDS plot, were tested using non-parametric analysis of similarities (ANOSIM) (Clarke \& Green 1988).

In order to understand the observed differences in flux patterns between sediment with TBT additions and control sediments, and in order to try to elucidate how TBT affected the sediment community, individual fluxes were studied. Regression analysis was performed using the 6 measurements from different occasions to see if the magnitude of fluxes changed significantly during the experiment and, if so, to what extent. If a flux changed with time, the total change during the experiment was calculated by subtracting the final flux from the initial flux. Total change as well as initial and final fluxes were then compared between the boxes with TBT additions and the control boxes.
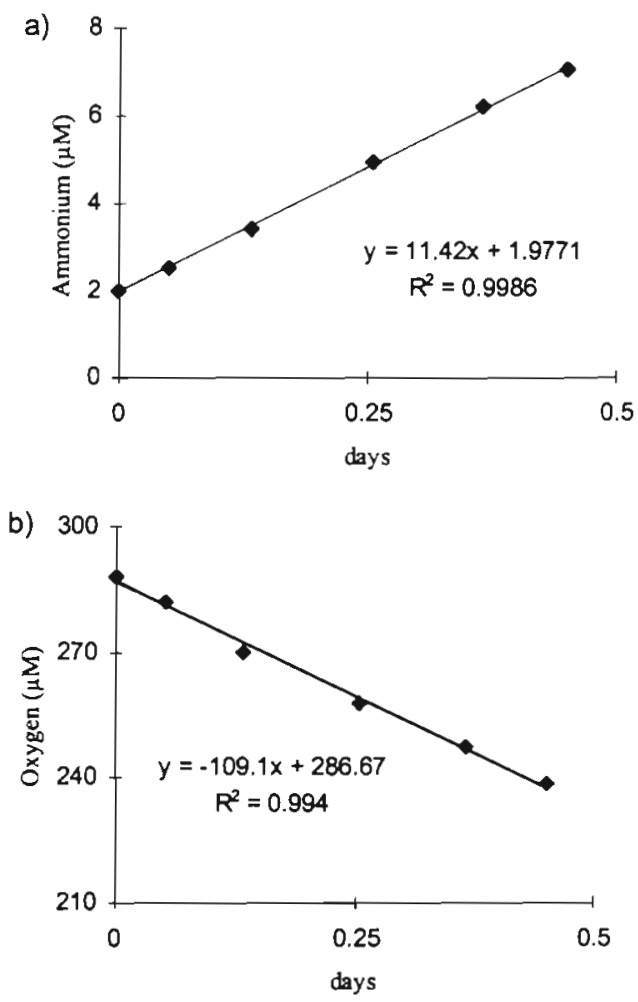

Fig. 4. Example of a flux measurement in the sediment boxcosm. (a) Flux of ammonium from sediment to water, (b) Flux of oxygen from water to sediment. Fluxes in each box on each occasion were calculated as the increase/decrease of the concentration of the solute with time. By taking the volume of the water and the area of the sediment surface in each box into account, the flux in $\mu \mathrm{mol} \mathrm{m}^{-2} \mathrm{~d}^{-1}$ can be calculated. Slopes are significant at $p<0.005$

\section{RESULTS}

Twenty-four hours after the addition of sediment slurry, when the overlying water mass was clear enough, direct effect of the TBT addition on the macro fauna could be seen. Sea urchins in the boxes with the 5 highest additions had been running through the sediment, making deep paths in the surface sediment. Two days later, heart urchins, brittlestars and small bivalves Abra alba had crept up to the sediment surface in the boxes with the 4 highest additions, 13.7 to $137 \mu \mathrm{mol}$ added TBT $\mathrm{m}^{-2}$. After $3 \mathrm{wk}$, between 30 and 50 brittlestars and a number of heart urchins were lying on the sediment surface in the boxes with the 3 highest additions of TBT. After $6 \mathrm{wk}$, the fauna on the sediment surface in these boxes had started to decay and spots of sulphide were seen around the decaying fauna. There was no visual evidence of disturbed fauna in any of the other boxes with TBT additions, nor in the control boxes at this time.

TBT already affected the flux pattern at the lowest addition of $0.0065 \mu \mathrm{mol}$ added TBT $\mathrm{m}^{-2}$, as shown in 


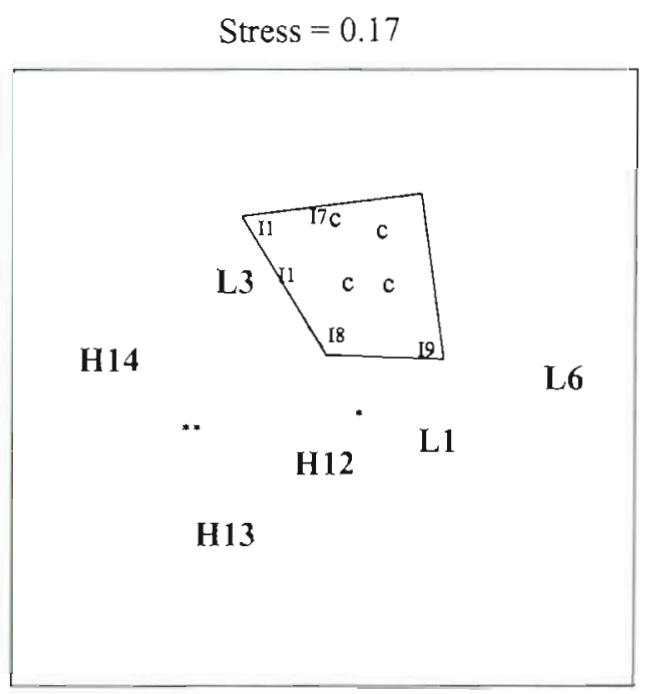

Fig. 5. Similarity in nutrient flux patterns for sediment boxcosms treated with TBT The MDS-ordination of the BrayCurtis indices is shown, reflecting differences in flux patterns. The 2 groups marked with dotted lines were tested for significant differences with the group containing the controls (solid line), using ANOSIM analysis. " $p<0.009, \cdots p<0.005$. Numbers indicate the TBT treatment number (see Table 2) and ' $c$ ' control sediments. Treatments $2,4,5$ and 15 were lost at the beginning of the experiment. $\mathrm{H}$, I and L: high, low and intermediate TBT exposures as defined in the ANOSIM analysis. Ammonium, nitrate, silicate and oxygen fluxes are included

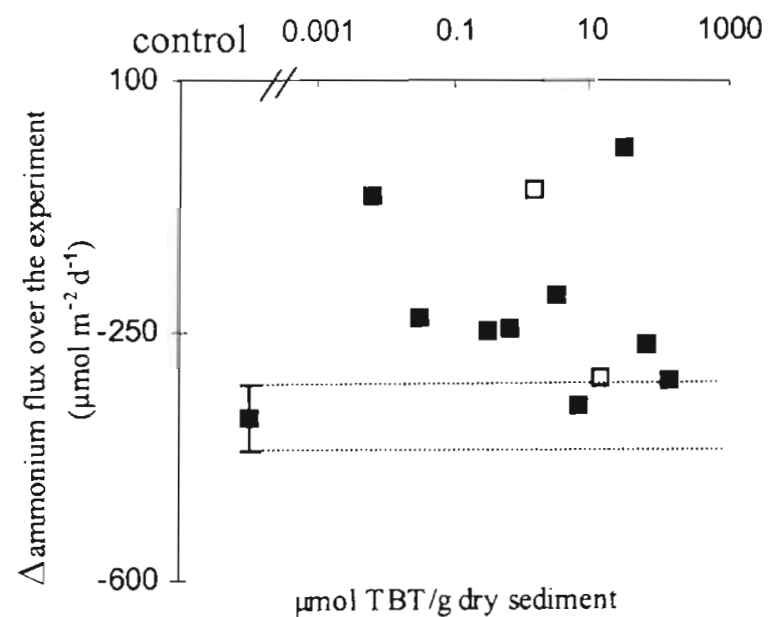

Fig. 6 Difference between the initial and final ammonium flux in sediment boxcosms due to TBT. Ammonium flux of the sediments decreased during the experimental period. Dotted line: $95 \%$ confidence interval of the decrease in ammonium flux in the control boxes. Most boxes with TBT additions had a smaller decrease in ammonium flux compared to the control boxes. The decrease in ammonium flux during the experiment had a significant negative regression at $p<0.05$ for all treatments, apart from no. 12 (口), where the decrease was significant at $p<0.1$
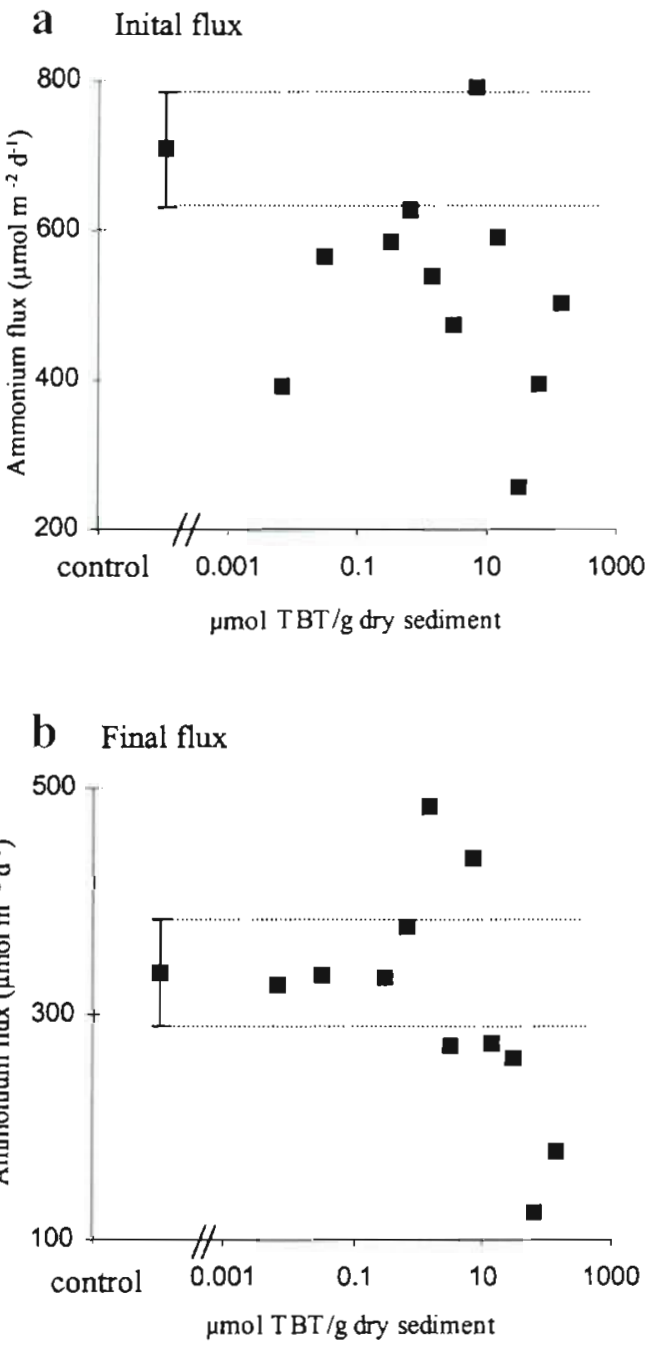

Fig. 7. Effect of TBT on ammonium flux in sediment boxcosms, initially and at the end of the experiment. Initial ammonium flux was reduced for all but one TBT addition. Final ammonium fluxes for all but 3 TBT additions were the same as the flux from the control boxes. Dotted line: $95 \%$ confidence interval of the control boxes

the MDS ordination (Fig. 5). Fluxes of ammonium, nitrate, phosphate and silicate from all 6 occasions and oxygen fluxes from the 5 last occasions were included in the multivariate analysis of the flux pattern. The MDS ordination could not fully represent the flux pattern, as indicated by the stress value of 0.17 . However, the ANOSIM indicated the presence of 3 different groups as outlined in the plot (Fig. 5). The 3 lowest and 3 highest additions differed significantly from the controls ( $\mathrm{p}<0.009$ and $\mathrm{p}<0.005$, respectively) while the intermediate additions of TBT (Treatments 7 to 11) were more similar to the control group.

In an attempt to understand the causes of the differences and similarities in the ANOSIM, the individual 


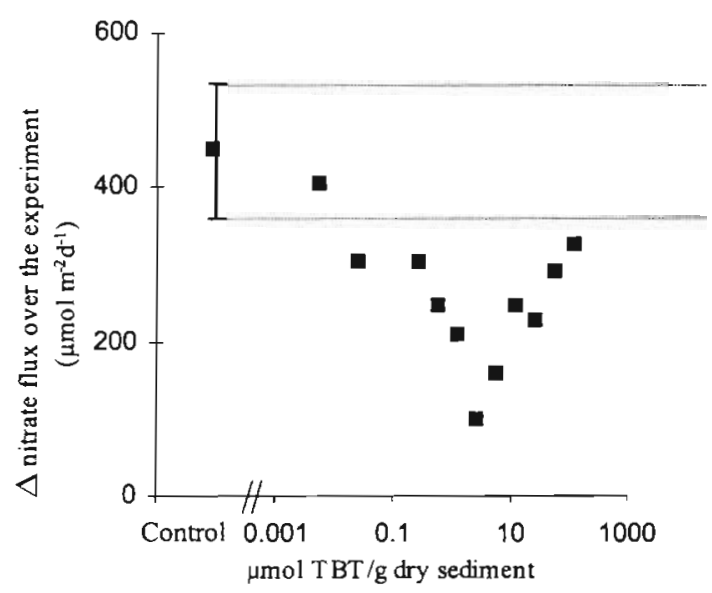

Fig. 8. Difference between the initial and final nitrate flux in sedirnent boxcosms due to TBT. Nitrate flux of the sediments increased during the experimental period. Dotted line: 95\% confidence interval of the increase in nitrate flux in the control boxes. Most boxes with TBT additions had a smaller increase in nitrate flux compared to the control boxes. The increase in nitrate flux during the experiment had a significant positive regression at $p<0.05$ for all treatments

fluxes were also evaluated. Effects of TBT were evident on the ammonium, nitrate, oxygen and silicate fluxes, whereas the phosphate flux displayed no TBTrelated response.

The ammonium flux decreased significantly $(\mathrm{p}<$ 0.05 ) with time in all boxes, but the degree of decrease differed between control boxes and boxes with TBT (Fig. 6). The ammonium flux changed more rapidly in the control boxes than in any of the boxes with TBT additions. However, the 3 highest additions had an increased ammonium flux between 2 and $6 \mathrm{wk}$ due to decaying fauna, after which the ammonium flux also decreased for these boxes. Initially (Fig. 7a) there was a reduction in ammonium flux for most TBT-added sediments compared to the flux from the control sediments, but at the end of the experiment (Fig. 7b) the ammonium flux in these sediments had reached the same level as in the control sediments.

The flux of nitrate increased significantly $(\mathrm{p}<0.05)$ in all the boxes during the experiment, but again the degree of change during the experiment differed between the sediments with TBT additions and the control sediments (Fig. 8). The increase in nitrate flux during the experiment was smaller for the sediments with TBT, apart from the lowest addition, than for the control sediments. The initial nitrate flux was stimulated in the boxes with TBT additions compared to the controls (Fig. 9a), but at the end of the experiment the nitrate flux from the control sediments was larger than that from the TBT treated sediments (Fig. 9b).
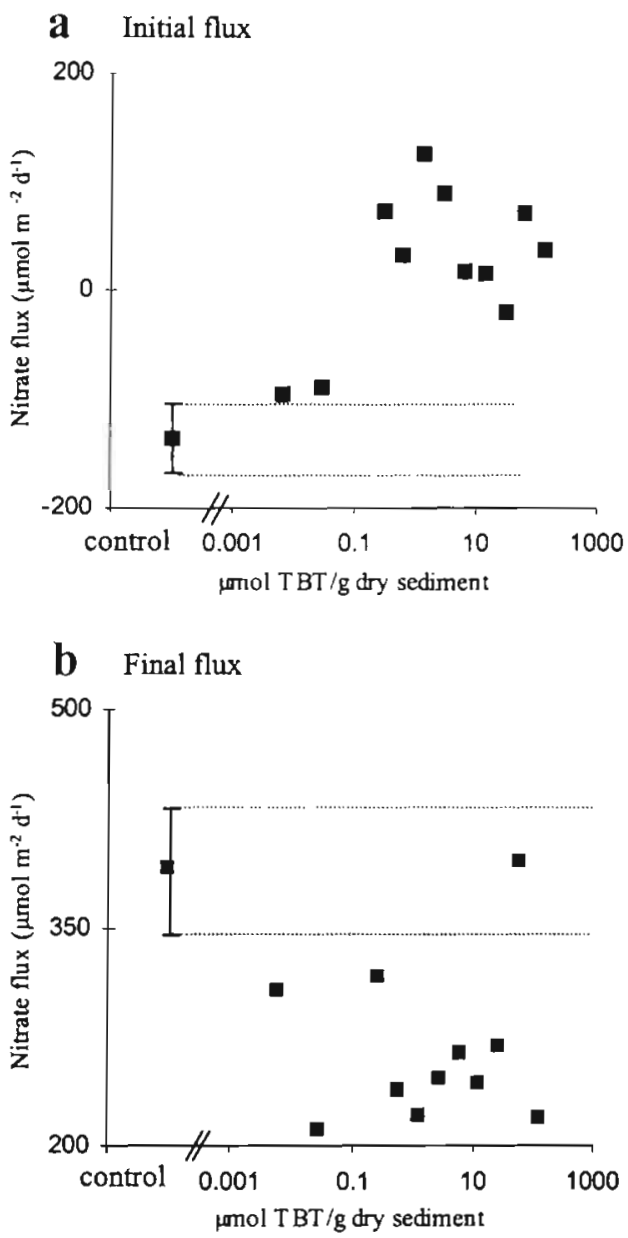

Fig. 9. Effect of TBT on nitrate flux in sediment boxcosms, initially and at the end of the experiment. Initial nitrate flux was stimulated for all TBT additions, whereas the final nitrate fluxes were lower compared to control for all but 1 TBT treatment. Dotted line: $95 \%$ confidence interval of the control boxes

TBT also affected the fluxes of oxygen. There were no changes in oxygen flux in the control boxes during the experiment, whereas the 3 lowest $(0.0065$ to $0.3 \mu \mathrm{mol}$ TBT $\mathrm{m}^{-2}$ ) and the 4 highest TBT additions showed a reduced oxygen flux with time (Fig. 10). In contrast, the 3 intermediate TBT additions ( 0.64 to $\left.3 \mu \mathrm{mol} \mathrm{TBT} \mathrm{m}^{-2}\right)$ showed an increase in the flux of oxygen with time.

The silicate flux was affected by TBT as well. In the 3 highest treatments ( 30 to $317 \mu \mathrm{mol}$ added TBT m${ }^{-2}$ ) the silicate fluxes were negatively affected after $3 \mathrm{wk}$, and remained negatively affected throughout the experiment (Fig. 11). These were the same boxes where death of fauna had been observed. Otherwise, there was no change in silicate flux for either control or TBT-treated sediments during the experiment.

All major fluxes were affected by TBT, but in different directions and at different TBT additions. The com- 


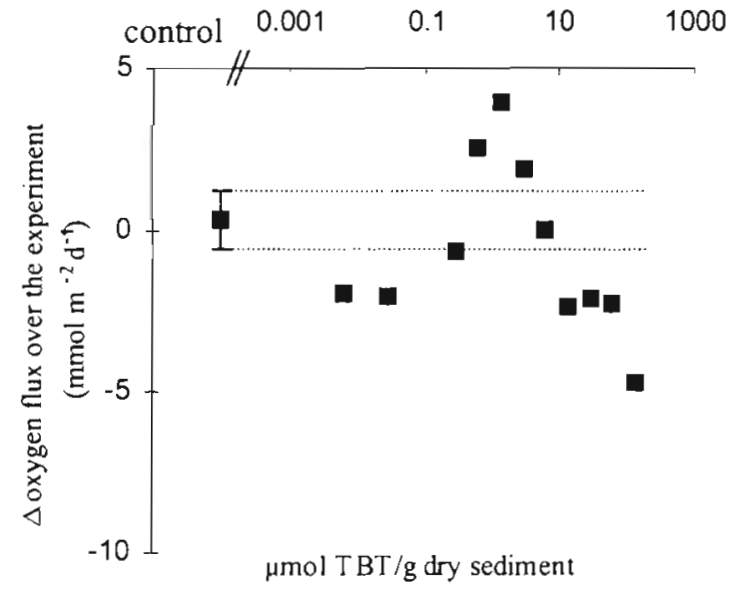

Fig. 10. Difference between the initial and final oxygen flux in sediment boxcosms due to TBT. In the 3 lowest TBT additions oxygen flux decreased with time, as it did in the 5 boxes with the highest additions. Three boxes with intermediate additions showed instead an increase in oxygen flux with time. Dotted line: $95 \%$ confidence interval of the control

bination of these effects is the reason for the grouping of the ANOSIM (Fig. 5), where the intermediate treatments appear to be the most similar to the control. Since the effects of TBT on fluxes is time dependent, the multivariate analysis provides an integrated summary of the effects, whereas the regression analysis of the individual fluxes shows the past and ongoing effects of TBT. Depending on when the ANOSIM is performed, different patterns will therefore emerge.

In our experiment TBT was allowed to adsorb to sediment particles from the sampling site immediately

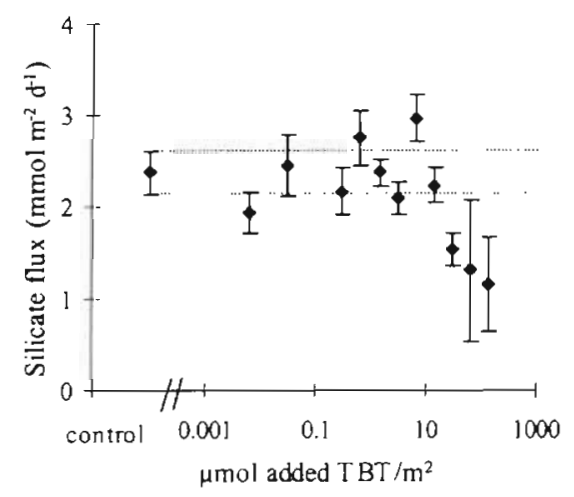

Fig.11. Effect of TBT on the silicate flux in sediment boxcosms. Silicate flux was constant in all but the 3 highest additions throughout the experiment. For the 3 highest additions the silicate flux was reduced after $3 \mathrm{wk}$ and then remained constant for the rest of the experiment. Each point is the average of 5 flux measurements with $95 \%$ confidence interval bars. The control flux is an average of the 4 control boxes at the 5 flux measurements before being added as a sediment suspension to the boxes. This TBT thus resembles TBT contamination reaching the sediment adsorbed to particles settling from the pelagic zone. TBT concentrations in the top centimetre of the sediment were determined at the end of the experiment in the remaining 14 boxes (Table 1). Only boxes with the 6 highest additions of TBT had a higher measurable TBT concentration than the background concentration in the control boxes. The concentrations of TBT in the top centimetre in these boxes were 5 to 20 times lower than expected if all of the added TBT had stayed within the top centimetre (Table 1). This dilution of TBT was probably caused both by vertical mixing by fauna and by bioaccumulation. The concentration of DBT was higher than the background in the boxes with the 2 highest TBT additions. The increase in DBT concentration was about 10 times lower than the increase in concentration of TBT, suggesting that no more than $10 \%$ of the TBT was transformed to DBT during the experiment. The additions of TBT to the other boxes were too small to be detected, since they were smaller than the current precision for TBT analysis. The TBT exposure is therefore indicated by the nominal additions of TBT per square metre of sediment.

\section{DISCUSSION}

TBT affected the biogeochemical processes of a marine sediment system at very small additions of TBT. The pattern of fluxes of inorganic nutrients and oxygen over the sediment surface already responded at $0.0065 \mu \mathrm{mol}$ added TBT $\mathrm{m}^{-2}$. This TBT addition corresponds to a concentration increase of $2 \mathrm{pmol} \mathrm{g}^{-1} \mathrm{dw}$ in the top centimetre of the sediment, provided that no losses occur. If we assume a reasonable redistribution of the added TBT due to bioturbation in the top $10 \mathrm{~cm}$ where $90 \%$ of the fauna resides, the lowest concentration increase which caused a significant effect on sediment fluxes is 0.2 to $2 \mathrm{pmol}$ added TBT $\mathrm{g}^{-1}$ dry sediment. This addition is too small to be detected with the current precision of TBT analysis in sediment and 5 times lower than the threshold concentration $\left(3 \mathrm{ng} \mathrm{g}^{-1}\right.$ $\mathrm{dw}$ ) of TBT in marine sediments, classified by Dowson et al. (1993) as 'non-contaminated'. We have to conclude that even minute additions of fresh TBT to a marine sediment system can cause perturbations of its ecological functions. However, the matter is more complicated than that. The sediment for the boxcosms were sampled from the Gullmar Fjord in Sweden, which like most coastal areas has a background TBT contamination. This was estimated by chemical analysis to be 83 pmol TBT $\mathrm{g}^{-1}$ dry sediment $\left(-27 \mathrm{ng} \mathrm{g}^{-1}\right)$, classified as a moderately contaminated site according 
to Dowson et al. (1993). We thus had a situation where a concentration increment of 0.2 to 2 pmol TBT $\mathrm{g}^{-1}$ dry sediment caused a disturbance even though the sedi-

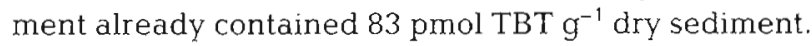
This is, however, in line with results from short-term incubations, where effects of TBT were seen at even lower additions (0.25 fmol TBT $\mathrm{g}^{-1}$ dry sediment) to sediment from the same site (Dahllöf et al. 1999). We have no final explanation for the effect of such low additions, but it seems reasonable to assume that bioavailablity of TBT could be of importance. Few studies of TBT and bioavailablity have been made, but Fent \& Looser (1995) showed that humic acids made TBT less bioavailable to Dahpnia and Thymallus thymallus. Since humic acids are a large part of the organic matter in marine sediments, it is likely that TBT becomes less bioavailable with time due to association with these humic substances. Freshly added TBT as in our experiments would therefore represent a more bioavailable fraction.

The effect of TBT on the flux pattern was evident from the ANOSIM (Fig. 5), which indicated an impact of TBT in the 3 lowest additions as well as in the 3 highest additions, whereas the intermediate additions had flux patterns similar to the controls. A similar $3-$ phased response can be also be seen in the flux of the individual nutrients.

Our experiment was not designed to explain the complicated relation that we observed between TBT exposure and the response of the sediment community. We can therefore only speculate on the causal links behind the different responses that we found after low, intermediate and high TBT exposure, respectively. There is, however, evidence to suggest reasonable interpretations of the observed effects.

We suggest that the effect of TBT at low exposure was mainly on microbiota. The initial TBT effects were decreased ammonium and increased nitrate flux (Figs. 7a \& 9a). This is very similar to what we observed earlier in short-term incubations of sediment where we focused on microbiota, and fauna $>250 \mu \mathrm{m}$ had therefore been excluded (Dahllöf et al. 1999). It was concluded from these short-term experiments that TBT stimulated autotrophic nitrification due to uncoupling of the electron transport chain, thus causing oxidation of ammonium to nitrate but without efficient ATP production. This initial stimulation would lead to reduced nitrification after a while, since reduced ATP production in the nitrifiers would negatively affect their growth rate and abundance. This is consistent with the reduced nitrate flux at the end of the experiment for all but one TBT addition (Fig. 9b). In the short-term study (Dahllöf et al. 1999), the sediment microbiota also showed a reduced capability to degrade organic matter. This is consistent with the reduced ammonium flux (Fig. 7b) at the end of the experiment, and the reduced consumption of oxygen during the experiment (Fig. 10). It appears that earlier observations of short-term effects on microbiota in sediments without macrofauna provide a plausible explanation for the long-term effects of minute quantities of newly added TBT.

At intermediate TBT exposure the initial response of reduced ammonium flux and increased nitrate flux is much the same as for the lowest additions (Fig. 7 a). However, smaller increase in nitrate flux and the increase in oxygen flux during the experiments also suggest effects on other parts of the community than the micro-organism (Figs. $8 \& 10$ ). We suggest that TBT, accumulating in fauna during the experiment at intermediate exposure, finally reaches a level at which TBT induces a toxic response. TBT is a known uncoupler of the proton gradient in cells, thereby disrupting the ATP production (Tosteson \& Wieth 1979. Antonenko 1990). This disruption would lead to the observed increase in oxygen consumption, since the fauna has to consume (oxidise) more organic matter to compensate for the low efficiency of respiration under uncoupling conditions.

We suggest that the impact on nutrient fluxes under high TBT exposure was mainly due to effects on larger fauna. However, this does not exclude concomitant effects on micro-organisms, especially since the initial and final effect of TBT on the nitrogen fluxes was similar at all the TBT exposures (Figs. $7 \& 9$ ). However, the changes of fluxes over time, with an increase in ammonium flux between Weeks 2 and 6, together with the drastic change in silicate flux (Fig. 11) are markedly different from changes in these fluxes in the lower additions. In the 3 highest additions fauna were seen to be stressed and die. The increase in ammonium flux in these boxes during Weeks 2 and 6 is most likely due to decaying fauna. The dissolution of silicate is largely an abiotic process (Iler 1979), making the silicate flux dependent only on the irrigation rate in the sediment. The changes in silicate flux in the 3 highest treatments are therefore the result of reduced irrigation due to a reduced number of fauna in the sediment. There was also a reduced oxygen flux in the highest treatments, which would be due to reduced fauna respiration due to lethality and also in part by a reduced capability by micro-organisms to degrade organic matter.

The development in the control boxes with time showed a shift from ammonium as the dominating nitrogen flux to nitrate. This shift was also reflected in the small increase in oxygen consumption in the control boxes. There was, however, no change in total inorganic nitrogen circulation (Fig. 12a,b), which indicates that there was no lack of available organic matter for mineralisation during the experiment. If there had 

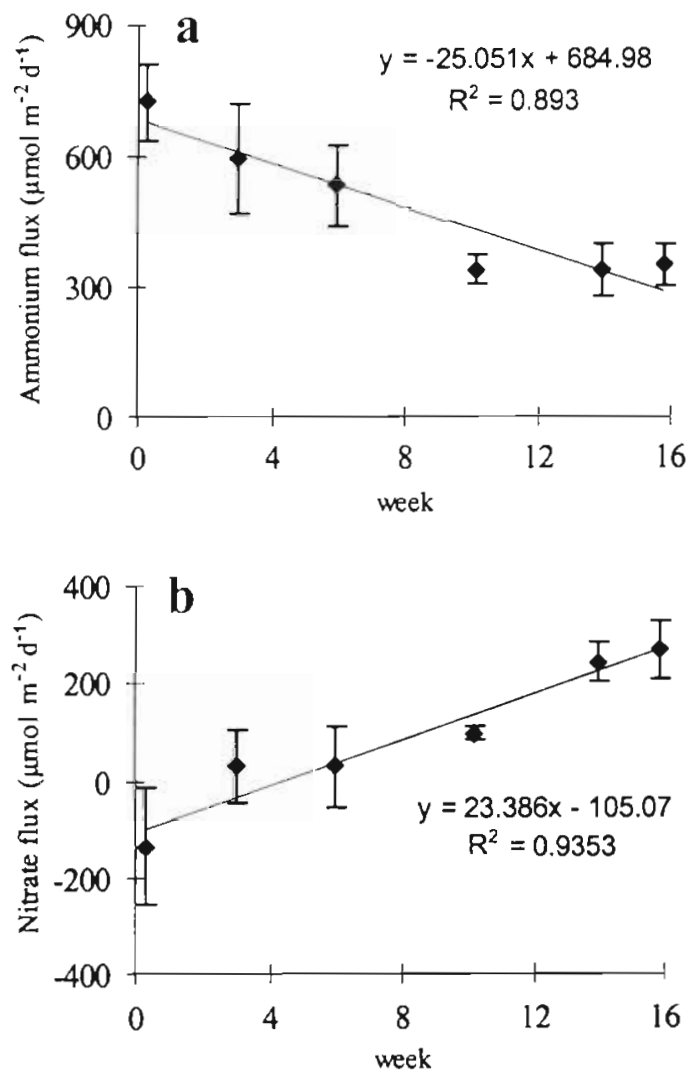

Fig. 12. Flux of (a) ammonium and (b) nitrate in the control boxes during the experiment. There was no change in total dissolved inorganic nitrogen flux with time. Slopes are significant at $p<0.04$

been a shortage of organic matter, the oxygen flux would also have been reduced. The more likely explanation to the shift in nitrogen metabolism would therefore be that the oxygenated zone in the sediments increased due to the experimental design with a constant supply of highly oxygenated water. TBT affected the flux pattern at very small additions. The nutrient fluxes are one of the links between the sediment and the rest of the marine ecosystem. A changed flux pattern could therefore also influence other parts of the ecosystem such as the primary producing algae. The reduced capability to degrade organic matter could also change the sediment environment itself and thereby cause changes in the structure of the sediment community. However, the ammonium fluxes in the TBT-treated sediment were similar to the fluxes from the control sediments at the end of the experiment, which could be interpreted as a sign of recovery. We cannot exclude this possibility, but other factors suggest that the apparent similarity in fluxes at the end of the experiment were not due to recovery. For example, it is obvious that the TBT-treated sediment where fauna died off could not become similar to the control sediments again in the time frame of the experiment. In order to fully evaluate apparent recovery of the sediment system, structural studies of the micro-organisms would also be needed. Attempts to detect a change in microbial structure were made at the end of the experiment. No perfect method for structural changes was available, but changes in the function of micro-organisms were indicated. It is therefore likely that the effect of TBT also led to structural changes in the micro-organism community, making recovery unlikely in any of the boxes with TBT additions during this experiment. Changes of structure in the microbial community due to TBT will be pursued in future experiments.

The addition of TBT in this experiment was made by adding spiked sediment to an already contaminated sediment. Most sediments in coastal areas close to frequent shipping activity are still being contaminated. This experiment is therefore similar to a situation where TBT released from boat hulls adsorb to particles in the water mass and settle on the sediment surface. The procedure of spiking a sediment probably leads to increased bioavailability of the added TBT compared to the TBT already present. How well these additions of spiked sediment resemble TBT sedimentation rates and bioavailability of settling TBT in coastal areas is not known. TBT measurements in the watercolumn are normally of total TBT, but in the future the fractionation of TBT between the waterphase and particulate organic matter should be investigated. It is also evident from our study that the sediment cannot be regarded only as a source or a sink for TBT, but that the function of the sediment must also be taken into account when assessing TBT effects.

Acknowledgements. We are grateful to K. Magnusson, S Agrenius and to other staff at Kristineberg Marine Research Station, and in particular to the crew of RV 'Arne Tiselius', for valuable assistance. Financial support was given mainly by the Swedish Environmental Protection Agency (NV) and the Ax:son Johnson Foundation. Additional funding was provided by the Hierta-Retzius' Foundation and the Adlerbert Foundation.

\section{LITERATURE CITED}

Aller RC (1982) The effects of macrobenthos on chemical properties of marine sediment and overlying water In: McCall L, Tevesz MJS (eds) Animal-sediment relations. Plenum, Princeton, p 53-102

Aller RC (1994) Bioturbation and remineralization of sedimentary organic matter: effect of redox oscillation. Chem Geol 114:331-345

Alzieu C, Héral M, Thibaud Y, Dardignac MJ, Feuille $M$ (1981-1982) Influence des peintures antisallisures à base d'organostanniques sur la calcification de la coquille de l'huitre. Crassostrea Gigas Rec Trav Int Pêches Marit 45: $101-116$

Antonenko YN (1990) Electrically silient anion transport 
through bilayer lipid membrane induced by tributyltin and triethyllead. J Membr Biol 113:109-113

Austen MC, McEvoy A.J (1997) Experimental effects of tributyltin (TBT) contaminated sediment on a range of meiobenthic communities. Environ Pollut 96:435-444

Bergeron V, Blais JS, Wharf I, Marshall WD (1993) Toxicity of tributyltin chloride to anaerobic nitrogen transformations in sediment and porewater. J Environ Qual 22: $528-536$

Blanck H, Dahl B (1996) Pollution-induced community Tolerance (PICT) in marine periphyton in a gradient of tri- $n$ butyltin (TBT) contamination. Aquat Toxicol 35:59-77

Bryan GW, Gibbs PE (1991) Impact of low concentrations of tributyltin (TBT) on marine organisms: a review. In: Newman MC, Mclatosh AW (eds) Metal ecotoxicology. Lewis Publishers, Chelsea, p 323-361

Cairns JJ (1983) Are single species toxicity tests alone adequate for estimating environmental hazards. Hydrobiologica 100:47-57

Champ MA. Wade TL (1996) Regulatory policies and strategies for organotin compounds. In: Champ MA, Seligman PF (eds) Organotin. Environmental fate and effects. Chapman \& Hall, London, p 55-94

Clarke KR, Green RH (1988) Statistical design and analysis for a 'biological effects' study. Mar Ecol Prog Ser 46: $213-226$

Clarke KR, Warwick RM (1994) Change in marine communities: an approach to statistical analysis and interpretation. Natural Environment Research Council, Plymouth

Cooney JJ, Wuertz S (1989) Toxic effects of tin compounds on microorganisms. J Ind Microbiol 4:375-402

Dahllöf I, Blanck H, Hall P (1999) Short-term effects of tri-nbutyl-tin on marine sediment samples, using nutrient fluxes as effect indicators. Environ Toxicol Chem 18:850-857

Dowson PH, bubb JM, Lester JN (1993) Temporal distribution of organotins in the aquatic environment. Mar Pollut Bull $26: 487-494$

Fent K, Looser PW (1995) Bioaccumulation and bioavailablity of tributyltin chloride-influence of $\mathrm{pH}$ and humic acids. Water Res 29:1631-1637

Iler RK (1979) The chemistry of silica. John Wiley \& Sons, New York

Editorial responsibility: Otto Kinne (Editor),

Oldendorf/Luhe, Germany
Jude F, Lascourreg JF, Capdepuy M, Quentin C, Caumette P (1996) Evalutation of tributyltin resistance in marine sediment bacteria. Can J Microbiol 42:525-532

Kimball KD, Levin SA (1985) Limitations of laboratory bioassays: the need for ecosystem-level testing. Bioscience 35 : $165-171$

Landis WG, Matthews RA, Matthews GB (1997) Design and analysis of multispieces toxicity tests for pesticide registration. Ecol Appl 7:1111-1116

Langston WJ, Pope ND (1995) Determinants of TBT adsorption and desorption in estuarine sediments. Mar Pollut Bull 31:32-43

Levin SN (1989) Theoretical and methodological reasons for variability in the responses of aquatic ecosystem processes to chemical stresses. In: Levin SA, Harwell MA, Kelly JR, Kimball KD (eds) Ecotoxicology: problems and approaches. Springer-Verlag, New York, p 145-179

Libes SM (1992) An introduction to marine biogeochemistry. John Wiley \& Sons, New York

Meador JP, Krone CA, Dyer DW, Varanasi U (1997) Toxicity of sediment-associated tributyltin to infaunal invertebrates: species comparison and the role of organic carbon. Mar Environ Res 43:219-241

Miller ME, Cooney JJ (1994) Effects of tri-, di-, and monobutyltin on heterotrophic nitrifying bacteria from surficial estuarine sediments. Arch Environ Contam Toxicol 27: 501-506

Pratt JR, Cairns J (1996) Ecotoxicology and the redundancy problem: understanding effects on community structure and function. In: Newman MC, Jagoe $\mathrm{CH}$ (eds) Ecotoxicology: a hierarchial treatment. CRC Press, Boca Raton, p 347-370

Santschi P, Höhener P, Benoit G, Buchholtz-Ten Brink M (1990) Chemical processes at the sediment-water interface. Mar Chem 30:269-315

Tosteson MT, Wieth JO (1979) Tri-butyl-tin-mediated exchange diffusion of halides in lipid bilayers. J Gen Physiol 73:789-800

Waldock MJ, Waite ME, Miller D, Smith DJ, Law RJ (1989) The determination of total tin and organotin compounds in environmental samples. Ministry of Agriculture, Fisheries and Food, Lowestoft

Submitted: March 2, 1998; Accepted: June 8, 1999

Proofs received from author(s): October 21, 1999 